\title{
Impact of Livelihood Diversification on Rural Households' Income: The Case of Gamo Zone, Southern, Ethiopia
}

\author{
Wanno Wallole Wabara \\ Ph.D. Scholar, Wolaita Sodo University, School of Graduate Studies, Department of Rural Development and \\ Agricultural Extension, Wolaita Sodo, SNNPRS, Ethiopia
}

\begin{abstract}
Livelihood diversification strategy is playing an important role to generate rural household's income. This study focused on the impact of livelihood diversification on rural household's income in Kamba and Arbaminch Zuria woreda in Gamo Zone, Southern Ethiopia. The study is conducted by using a cross-sectional research approach. This study employed multi-stage random sampling technique, a sample size of 400 household individuals from 6 sample kebeles were selected. Inferential statistics wereused to examine the impact of livelihood diversification on households' income by using propensity score matching model (PSM). The econometric analysis result demonstrated thatout of 10 hypothesized explanatory variables, 6 variables which are age, sex, and religious, education in year, extension service and access to market were found to have significant impact on livelihood diversification.Age and Religious influenced the probability of participation in diversification positively and significantly at $5 \%$ level. Whereas the education in year were determined the participation of diversification positively and significantly at $(\mathrm{p}<0.001)$. And sex affected participation negatively at $10 \%$ significance level. On the other hand Extension Service and Access to Market affected participation negatively at 1\% and 5\% significance level, consecutively. Therefore, the findings of this imply that rural households' development policies should consider livelihood diversification is the right way to improvethe rural household's income.
\end{abstract}

Keywords: Livelihood; Diversification; income; PSM; Ethiopia.

DOI: $10.7176 / \mathrm{JESD} / 11-23-02$

Publication date: December $31^{\text {st }} 2020$

\section{Introduction}

Livelihood diversification is one of the most remarkable characteristics of rural livelihood strategy. It is a process of building rural households' capital by pursuing different group of activities to advance their standard of living (Ellis, 1998). Rural households' world-wide engage in a variety of non-farm activities to generate income (Lanjouw and Lanjouw, 2001; World Bank, 2003; Umunnakwe, 2015).

Households that have diversified income sources have better welfare indicators in terms of food security, healthcare, and affording school fees among others (Riithi, 2015). According to Barrett et al., (2001), diversification can be measured by using activities, income and assets. Households use both productive assets, mainly land and human capital, and unproductive assets such as household items and property and engage in various activities to generate income. Thus, assets, activities, and income can serve as complementary indicators of diversification (Barrett et al., 2001; Zerihun, 2017).

The contribution of non-farm income to rural income shares cannot be underestimated.In Latin America and the Caribbean, estimates of rural non-farm income shares for rural households were 22 per cent in Honduras, 59 per cent in Costa Rica and 68 per cent in Haiti (Reardon, 1997; Umunnakwe, 2015).In Africa also, various studies have shown that while most rural households are involved in agricultural activities as their main source of livelihood, they also engage in other income generating activities to augment their main source of income (Abimbola and Oluwakemi, 2013). Similarly a study indicated in Kamba woreda in Gamo Zone, Ethiopia nonfarm livelihood diversification activities could become good-looking alternatives to farming families' income. The study also indicated that only focusing on agricultural production may not be enough to generate sufficient and secure livelihoods.

Recently, evidences show that Ethiopia's rural people are vulnerable to poverty, food insecurity, limited access to social and health services, and limited options for livelihoods diversification and security. Due to this, their ability to lead a sustainable livelihood is challenged. Some Ethiopians are often unable to achieve household food security as a result of unreliable sources of income, instability in their livelihoods, and lack of diversified livelihoods (Fassil and Elias, 2016).

The increasing importance of rural livelihood diversification in Ethiopia has drawn the attention of various scholars in recent years. For instance, Fassil and Elias (2016) and (Melkamu and Mesfin, 2015) has shown the determinants of off-farm income diversification and its effect on rural household poverty in Gamo Zone Chencha, Kamba, and Mirab Abaya Woredas. However, these studies have missed key issues regarding the extent and impact of livelihood diversification roles to income improvement based on sound theoretical conceptual and methodological models. Hence, this paper is aimed at addressing such knowledge and improvement gaps in this particular research targeted areas. Specifically this paper explores the impact of livelihood diversification and their 
contribution to rural households' income in Kamba woreda in Gamo Zone.

\section{Methodology}

\subsection{The study area}

The study was conducted in Gamo zone, kamba and Arbaminch zuria woreda which is located in Southern Ethiopia. Gamo Zone has a total area of $12581.4 \mathrm{~km}^{2}$ and consists of 14 Woreds and the general elevation of the zone ranges from 600 to 3300 masl. The topography of the land characterizes an undulating feature that favors the existence of different climatic zones in the area. The total population of the zone is estimated about 1,597,767 with a population density of 80 inhabitants per kilometer square. The total population estimation of the Kamba woredais 155,748 which is about 9.76 percent of the zonal population. From the total population of the woreda, about 50 percent were females. And the total population estimation of the Arbaminch zuria woreda is 182,986 in 2011. Of which 91,420 (49.96 percent) are men and 91,566 (50.04 percent) are women (National Plan Center report, 2016/17).

\subsection{Sampling Techniquesand Methodsof Data Collection}

In order to select the representative sample household heads in the study area a multi-stage random sampling technique was applied. Hence, to select the two Woredas' out of fourteen Zonal Woredas' the researcher was used purposive sampling technique. The reasons that the researcher was used purposive sampling technique to select two Woredas are based on similar of agro-ecologic zone (high land, midland and low land). Besides they have common characteristics of income generating activities like on-farm, non-farm and off-farm activities. In this manner in the first stage, two Woredas namely; Kamba and Arbaminch Zuria was selected among fourteen Woredas' to find out the impact of rural households' livelihood diversification in the rural household income.

In the second stage, six kebeles namely; Balta Toylo, Lae Geta Fudale, Otolo from Kamba Woreda; Ganta Merice, Ganta Bonke, and Chano Dorga from Arbaminch Zuria Woreda have been selected based on stratified random sampling technique to consider three agro-ecological zones (high land, mid land and low land). In the third stage, the participant's households were select by using a systematic random sampling technique from each kebele. In order to determine the representative sample sizes for the total target population of this study, the researcher was used the formula developed by Yamane (1967).

$$
n=\frac{N}{1+N(e)^{2}} \quad n=\frac{20,000}{1+20,000(0.05)^{2}} \quad n=400
$$

Based on this formula out of total population 20,000 households 400 sample household respondents were selected from six kebeles by systematic sampling technique, the numbers of male and female headed households in the sample were 288 and 112 respectively, while equal population proportion sample size was taken from two each woredas.

The study was used both primary and secondary data sources. Primary data were collected by key informant interview, interview schedule, and checklist. Secondary data were gathered from published and unpublished data sources. The study was applied a semi-structured household interview schedule for the household survey to analyze the variables. The study was also used checklists for observation, key informant interview and group discussion to ensure complementary and improvement of data validity and reliability.

\subsection{Methods of Data Analysis}

This research had applied a cross-sectional research approach in order to obtain pertinent information concerning the current experience of rural farmers on livelihood diversification and its impacts on households' income. Propensity Score Matching (PSM) econometric model was used to analysis the impact of livelihood diversification on the rural household income.

\subsection{Definition of Variables and their expected sign}

Age: is continuous variable and it refers to age of the household head and it is also measured in years. Therefore, this study expected that age is positively related to livelihood diversification.

Sex: It is dummy variable and it is an explanation of Men and women. Therefore, this study expected that men are positively related to livelihood diversification.

Religious: It is a categorical variable and it refers to the religious groups. Religious help households to make group to participate in livelihood diversification activities. Hence, this variable hypothesized positively and significantly affected the livelihood diversification.

Education of the head: It is a continuous variable and it refers to the level of education of household heads. Literate farmers are expected to be better than their illiterate counterparts in several ways. Therefore, this study hypothesized that education is positively related to livelihood diversification.

Marital Status: It is a categorical variable and it refers to the marital status of the households. Therefore, this study expected that married has positively related to livelihood diversification. 
Family-size: It is a continuous variable and it refers to the size of household members. Large family size demands a large amount of production to feed its members. Therefore, this study hypothesized a positive relationship between livelihood diversification and family size.

Extension contact: It is dummy variable or frequency of contact and it referees extension worker contact with farmers' in agricultural advice. Hence, extension worker contact to farmers' in agricultural advice hypothesized positively affect livelihood diversification in the study area.

Credit users: It is dummy variable and refers credit use. Households who have access and able to afford to credit will be able to diversify their livelihood strategies. Therefore, this study expected that access to credit service is positively related to livelihood diversification.

Market Distance: It is continuous variable and refers that road proximity to market or town has a significant influence on livelihood diversification and increases the prospects of non-farm employment for rural households. Thus, the relationship between livelihood diversification and the distance to the farthest town/market hypothesized negatively.

Cultivated Land: It is a continuous variable and it refers that the size of the cultivated land demands livelihood diversification. More cultivated land size holding means more cultivation and more possibility of production which in turn increases farm income and improves food security. Therefore, having large farm cultivated land size this study hypothesized to affect livelihood diversification negatively since the farmer relay on crop production than to go for off/ non-farm in order to satisfy basic needs.

Livestock holding : It is continuous variable and refers that households with more livestock holding do have the capacity to participate in lucrative non/off-farm employment activities than those households with no or small size livestock holding. Therefore, this study expected that of a higher amount of livestock holding is positively related to livelihood diversification.

\section{Result and Discussion}

\section{Impact of Livelihood Diversification on Rural Households' Income}

This specific objective of the study was to examine the impact of livelihood diversification on rural households' income in the study area. To examine this study score marching model was used. Owing to this model of examination, the PSM framework has been adopted for estimating the impact of livelihood diversification on household income. Impact through this outcome variable has been obtained by matching an ideal comparative group (non-diversified farmers) to the treatment group (diversified farmers) on the basis of propensity scores (Pscores) of $\mathrm{X} . \mathrm{X}$ is the set of observable characteristics that determine diversification participation. By so doing the selectivity bias is largely eliminated. It was also followed illustrates the logistic regression, estimation of propensity score, the common support region, choosing a matching algorism, matching quality, average treatment effect on the treated and sensitivity analysis.

\section{Logistic regression model result}

This section shows the result of propensity scores matching (PSM) in detail. To measure the average treatment effect on the treated (ATT) for intended outcome variable, a logit model was estimated in order to get the propensity scores. Before going to estimation variance inflation factor was done to test whether multicolinearity problems (VIF) exist or not. There was no explanatory variable dropped from the estimation model since no serious problem of multi-collinearity was detected from the VIF results which is very far less than 10 . Not only this test was also done using Breusch-Pagan / Cook-Weisberg test for and the P-value was 0.8152which is insignificant which show that there is no problem. After doing this a matching estimator that best fit to the data was selected. Then based on those scores estimated and matching estimator selected, matching between diversified and not diversified was done to find out the impact of the diversification on the mean values of the outcome variable. Therefore, this section illustrates all the required algorithms to calculate the average treatment effect on the treated, which helps us to identify the impact of diversification.

While, obtaining the propensity score matching estimator by starting through the logit regression, individual income status was used to form matched pairs of observational similar individual characteristics. Individual in households participating in diversification (the treatment cases) and households not participating (the controls) are considered. Therefore in this study the logit model for estimation of propensity score is presented in (Table 1) as follows. 
Table 1: Logit Model Estimates of the Effect of Livelihood Diversification on Household Income

\begin{tabular}{|c|c|c|c|c|}
\hline VARIABLES & COEFFICIENTS & STD.ERR. & Z-VALUE & P-VALUE \\
\hline cons & -2.811126 & .895659 & -3.14 & 0.002 \\
\hline $\mathrm{AGE}$ & .0219193 & .111521 & 1.97 & $0.049 * *$ \\
\hline SEX & .7387426 & .4346923 & 1.70 & $0.089 *$ \\
\hline RELIGIUS & .2660028 & .1189865 & 2.24 & $0.025 * *$ \\
\hline EDUYEAE & .6067223 & .0810397 & 7.49 & $0.000 * * *$ \\
\hline MARTAIL & .417356 & .2789148 & 1.50 & 0.135 \\
\hline FAMILYSIZE & -.0459825 & .0482056 & -0.95 & 0.340 \\
\hline EXTENTION & -1.258495 & .3394276 & -3.71 & $0.000 * * *$ \\
\hline CREDITUSE & .3374722 & .2911995 & 1.16 & 0.246 \\
\hline ACESSMKT & -.7086266 & .2970573 & -2.39 & $0.017 * *$ \\
\hline CULTIVATED & .116441 & .1820405 & 0.64 & 0.524 \\
\hline TLU & -.0046083 & .0216218 & -0.21 & 0.831 \\
\hline $\begin{array}{l}\text { Number of obs = } \\
\text { LR } \operatorname{chi}^{2}(11)= \\
\text { Prob }>\text { chi }^{2}= \\
\text { Log likelihood }= \\
\text { Pseudo } \mathrm{R}^{2}=\end{array}$ & & $\begin{array}{r}1 \\
0 \\
-19 \\
0\end{array}$ & $\begin{array}{l}4 \\
0 \\
431 \\
8\end{array}$ & \\
\hline
\end{tabular}

Source: Own survey. $* * *, * *$ and $*$ significant at $1 \%, 5 \%$ and $10 \%$ probability respectively

The logit result revealed a fairly low pseudo $\mathrm{R}^{2}$ of 0.2618 . The pseudo- $\mathrm{R}^{2}$ indicates how well the model explains the diversification probability (Caliendo and Kopeinig, 2005). A low $\mathrm{R}^{2}$ value means diversified households do not have much distinct characteristics overall and as such finding a good match between diversified and not diversified households becomes easier (Yibeltal, 2008). Secondly, the model has a chi-square static of 141.14, which is statistically significant at the 1 per cent confidence level, therefore implying that all the predicators that have been included in the model are capable of jointly predicting participation in the livelihood diversification (Table 1).

The logistic regression result shows that diversification is significantly influenced by six variables. These variables are Age (AGE), Sex (SEX), Religious (Religious), Education in year (EDUYEAE), Extension Service (EXTENSION) and Access to Market (ACCESSMKT) were found to significantly affect the probability of diversification. Age and Religious influenced the probability of participation in diversification positively and significantly at $5 \%$. Whereas the education in year were determined the participation of diversification positively and significantly at $(\mathrm{p}<0.001)$. On the other hand Extension Service and Access to Market affected participation negatively at $1 \%$ and $5 \%$ significance level, consecutively. And sexaffected participation negatively at $10 \%$ significance level.The distribution of propensity score for each household which included in the diversified and not diversified group was computed based on the above model (Table 1).

\section{Common support condition}

The next task in propensity score matching technique is to check the common support condition. Only observations in the common support region will be matched with the other group and others should be out of further consideration. Once the common support region is defined, individuals that fall outside this region have to be rejected and hence the treatment effect cannot be estimated.

The region of common support between treatment and control groups can be certified with relatively straightforward strategies. One obvious approach is through visual inspection of the propensity score distributions for both treatment and control groups. In this study, the visual analysis of the density distribution of the propensity score between two groups was used to confirm the common support region. It is supposed that the probability of participation in diversification, conditional on the observed characteristics, lies between 0 and 1 (implying participation is not perfectly predicted). Observations that had propensity scores which were lower than the minimum or higher than the maximum in the opposite group were removed from the sample. It is clear from the observation of Figure 1 that there is overlap between the treated and the control groups. However, according to the Dehejia and Wahba (2002) when there is substantial overlap in the distribution of propensity scores between the treated and control groups, matching techniques is performed only on the common support region. This can typically provide researchers a good, initial reading of the extent to which there is common support area in propensity scores of treatment and control units (Heinrich et al., 2010). Figure 1 shows that the common support condition is satisfied as there is overlap in the distribution of the estimated propensity scores for the two groups. In this case the matching procedure is only achieved on the region of common support. 


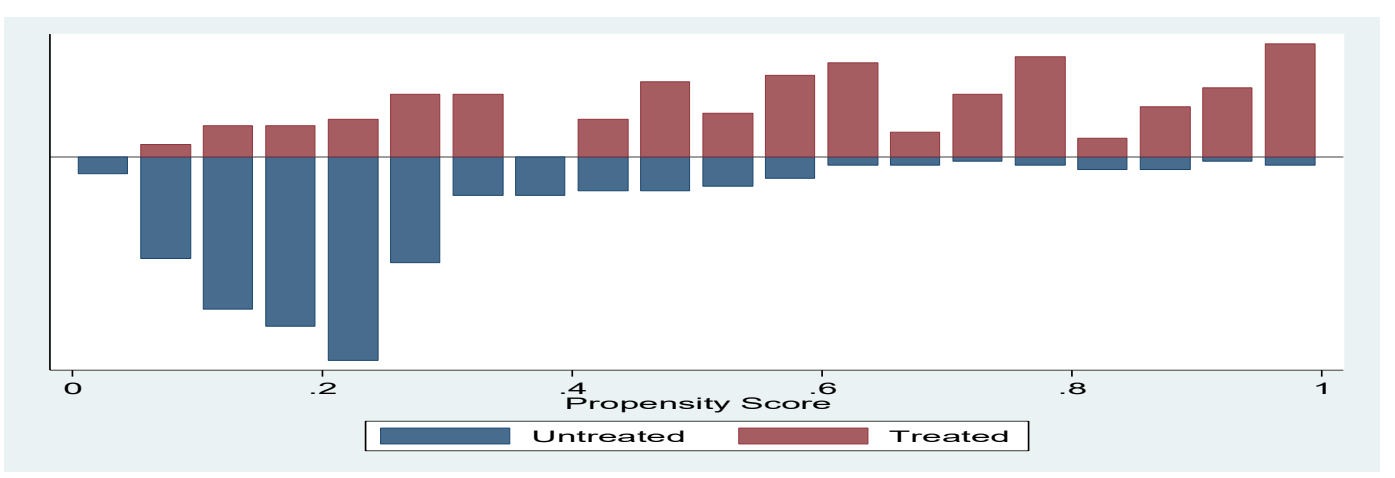

Figure 1: common support conditions

Source: Own survey (2019).

\section{Matching diversified and not diversified households}

Selecting matching estimator has it is own criteria. The final choice of a matching estimator was guided by different criteria such as equal means test referred to as the balancing test, pseudo-R2 and matched sample size (Dehejia and Wahba, 2002). Balancing test is a test conducted to know whether there is statistically significant difference in mean value of treatment characteristics of the two groups of the respondents and preferred when there is no significant difference. Accordingly, matching estimators were evaluated by matching the diversified and not diversified households in common support region. Therefore, a matching estimator having large balanced (insignificant mean differences in all explanatory variables) mean, bears a low pseudo $\mathrm{R}^{2}$ value, mean bias in between 3-5\% and also the one that results in large matched sample size is preferred. Based on these criteria, as shown in the (Table 2) Kernel with band width 0.1 was selected for matching this was because it had low $\mathrm{R}^{2}$ equal value, large number of sample size and balancing insignificant test.

Table 2:Performance of matching estimators

\begin{tabular}{|c|c|c|c|c|}
\hline \multirow[t]{2}{*}{ Marching estimators } & \multicolumn{4}{|l|}{ Performance criteria } \\
\hline & $\begin{array}{l}\text { Number of insignificant } \\
\text { variables after matching }\end{array}$ & $\begin{array}{l}\text { Pseudo-R }{ }^{2} \quad \text { after } \\
\text { matching }\end{array}$ & $\begin{array}{l}\text { Mean } \\
\text { SB }\end{array}$ & $\begin{array}{l}\text { Matched } \\
\text { sample size }\end{array}$ \\
\hline \multicolumn{5}{|l|}{ Nearest neighbor } \\
\hline Nearest Neighbor1 & 11 & 0.112 & 5.9 & 396 \\
\hline Nearest Neighbor2 & 11 & 0.112 & 4.6 & 396 \\
\hline Nearest Neighbor 3 & 11 & 0.112 & 3.3 & 396 \\
\hline Nearest Neighbor 4 & 11 & 0.112 & 2.7 & 396 \\
\hline Nearest Neighbor 5 & 11 & 0.112 & 3.7 & 396 \\
\hline \multicolumn{5}{|l|}{ Caliper } \\
\hline Caliper 0.01 & 11 & 0.112 & 5.7 & 388 \\
\hline Caliper 0.1 & 11 & 0.112 & 5.9 & 396 \\
\hline Caliper 0.25 & 11 & 0.112 & 5.9 & 396 \\
\hline Caliper 0.5 & 11 & 0.112 & 5.9 & 396 \\
\hline \multicolumn{5}{|l|}{ Kernel } \\
\hline Kernel (bw0.01) & 11 & 0.112 & 4.9 & 388 \\
\hline Kernel (bw0.08) & 11 & 0.112 & 3.3 & 396 \\
\hline Kernel(bw0.1) & 11 & 0.112 & 3.2 & 396 \\
\hline Kernel(bw0.25) & 11 & 0.112 & 5.3 & 396 \\
\hline Kernel(bw0.5) & 11 & 0.112 & 10.8 & 396 \\
\hline
\end{tabular}

Source: Own survey.

\section{Matching Quality}

Once the region of common support is preferred, the study was employed the balancing test to check whether the differences in the covariates in the treated and control groups in the matched sample have been eliminated after matching (Table 3). If the covariates are similar after matching, then the matched comparison group can be considered as an acceptably counterfactual (Lee, 2008). Even though there are numerous matching quality estimation approaches, the mean standardized bias, the pseudo $\mathrm{R}^{2}$, and the likelihood ratio test which are the most broadly used and suggested by Rosenbaum and Rubin (1985) adopted in this study.

For each covariate, standardized bias is stated as the difference of sample means in the treated and control samples as a percentage of the square root of the average of sample variances in the treated and control groups 
(Rosenbaum and Rubin, 1985). The main problem with using the standardized bias approach is that there is no perfect indication for the achievement of PSM. However, in empirical studies, it is often expected that the mean bias after matching is within the acceptable from range of 3-5\% (Caliendo and Kopeinig, 2008). (Table 6) indicated that the mean bias, after the matching, the mean bias is between $36.9 \%$ and $3.2 \%$. It is suggested that a critical level of $20 \%$ seems to be acceptable for matching quality (Rosenbaum and Rubin, 1985). Thus; the result of the mean bias is satisfactory for the process of matching in this study.

Another important method in assessing matching quality is pseudo- $\mathrm{R}^{2}$, one can re-estimate the propensity score on the matched sample, i.e. only on treated and matched untreated and compare the pseudo- $\mathrm{R}^{2}$ before and after matching (Sianesi, 2004). The pseudo- $\mathrm{R}^{2}$ indicates how well the regresses covariates explain the participation probability. After matching, the pseudo- $\mathrm{R}^{2}$ should be relatively low, meaning that there are no systematic differences in distribution of covariates between the treated and control groups. It has been indicated that the pseudo- $\mathrm{R}^{2}$ before matching was 0.112 while after the matching, the pseudo-R2 was 0.005 which implies that there was no the problem in the process of matching diversified with non-diversified households (Table 4).

The likelihood ratio (LR) test was used to check if the mean of the covariates differ significantly between treated and control groups. The basic assumption of this method is that before matching, both treated and control groups can be different in covariates, but after matching the difference is supposed to be statistically insignificant, as the covariates should be balanced in both groups by the matching (Caliendo and Kopeinig, 2008). Result of this study in (Table 3) presents the values of the likelihood ratio test of the regressors in the logit model of propensity score estimation before and after matching. The observation of these values indicates that they are significant before matching at less than $1 \%, 5 \%$ and $10 \%$ significant level, respectively but are not significant after matching $(\mathrm{p}=0.005)$. In other words, the likelihood ratio notes that the null hypothesis is not rejected after matching. In general, the combination of the three indicators (bias reduction, pseudo $\mathrm{R}^{2}$, and LR) allows this study to generalize that there is no considerable difference in the distribution of covariates after matching.

\section{Table 3: Balancing test for covariates}

\begin{tabular}{|l|l|l|l|l|l|l|}
\hline & \multicolumn{2}{|c|}{ Vefore matching N=(180) } & \multicolumn{2}{l|}{ After matching N=(165) } \\
\hline & Diversified=161 & $\begin{array}{l}\text { Not- } \\
\text { diversified239 }\end{array}$ & T-test & Diversified=161 & $\begin{array}{l}\text { Not- } \\
\text { diversified=239 }\end{array}$ & $\begin{array}{c}\text { T- } \\
\text { test }\end{array}$ \\
\hline AGE & 44.304 & 42.05 & $1.93 *$ & 44.304 & 44.584 & -0.23 \\
\hline SEX & .89441 & .82845 & $1.84 *$ & .89441 & .90062 & -0.18 \\
\hline Religious & 1.9752 & 1.7029 & $2.56 * *$ & 1.9752 & 2.0186 & -0.35 \\
\hline Eduyear & 3.5093 & 1.3598 & $9.82^{* * *}$ & 3.5093 & 3.7764 & -0.75 \\
\hline Marital & 1.1118 & 1.0837 & 0.59 & 1.1118 & 1.1429 & -0.50 \\
\hline TFamlysz & 6.6894 & 6.3598 & 1.17 & 6.9627 & 6.7361 & -0.92 \\
\hline Exten & .73913 & .90795 & - & .73913 & .73292 & 0.13 \\
\hline CREDITUSE & .24845 & .22176 & 0.62 & .24845 & .26708 & -0.38 \\
\hline ACESSMKT & .18634 & .42678 & - & .18634 & .221118 & -0.56 \\
\hline CULTIVATED & .77879 & .76757 & 0.15 & .77879 & .73707 & 0.69 \\
\hline TLU & 3.8042 & 3.1051 & 1.19 & 3.8042 & 3.2927 & 0.63 \\
\hline
\end{tabular}

Source: Own survey (2019) $* * *, * *$ and $* 1 \%, 5 \%$ and $10 \%$ degree of significant

Table 4: Chi square test

\begin{tabular}{|l|l|l|l|l|}
\hline Sample & Pseudo R2 & LR chi2 & P> chi2 & MeanBias \\
\hline Before matching & 0.112 & 60.19 & 0.000 & 16.3 \\
\hline After matching & 0.005 & 2.12 & 1.000 & 3.2 \\
\hline
\end{tabular}

Source: Own survey (2019).

\section{Treatment effect on treated}

This section of the study tries to disclose whether diversification brought a significant effect on households' income comparing between diversified and not diversified households. The result which is presented in (Table 5) shows that, diversification brought statically significant effect in households' total annual income. It has been found that diversification increase households' income increases by 4337.24 on average income. This result has been supported by (Omeoresh, Adewumi and Fadimula, 2010), Households having non and off-farm sources of income tend to easily become secured their income than households that do not have such access. The result of this study also supported by Nasaet.al 2010, the result shows that when comparing farmers on the basis of livelihood diversification in respect to income security, diversified farmers are relatively food secured than the undiversified farmers. 
Table 5: Average Treatment Effect on the Treated (ATET)

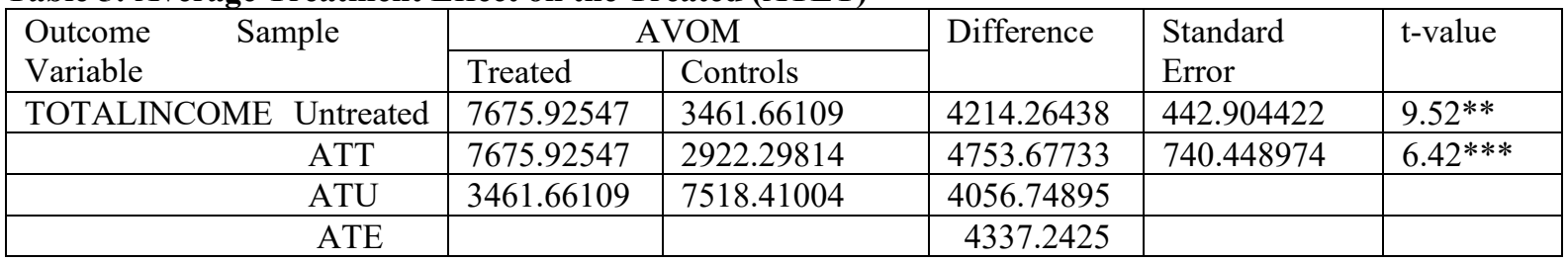

AVOM=Average value of outcome after matching; ATET=Average Treatment Effect on Treated; $* * * * *$ Significant at 5\%, 1\%, Source: survey data (2019)

Rosenbaum (2002), proposes using Rosenbaum bounding approach in order to check the sensitivity of the estimated ATT with respect to deviation from the CIA. The basic question to be answered here is whether inference about treatment effects may be altered by unobserved factors. In other words, one wants to determine how strongly an unmeasured variable must influence the selection process in order to undermine the implications of matching analysis. In order to control for unobservable biases, (Table 8) shows the result of sensitivity of livelihood diversification effects on income.

Table 6: Result of sensitivity analysis using Rosenbaum bounding approach

\begin{tabular}{|l|l|l|l|l|}
\hline Outcome & Gamma 1 & Gamma 1.25 & Gamma 1.75 & Gamma 2 \\
\hline TotaIncome & $\mathrm{P}<0.000$ & $\mathrm{P}<0.000$ & $\mathrm{P}<0.000$ & $3.9 \mathrm{e}-08$ \\
\hline
\end{tabular}

Source: Own survey (2019).

Result shows that the inference for the effect of the livelihood diversification is not changing though the diversified and not diversified households has been allowed to differ in their odds of being treated up to $100 \%$ (2) in terms of unobserved covariates. That means for the outcome variable estimated, at various level of critical value of gamma, the p- critical values is significant which further indicate that the study considered important covariates that affected both diversification and income. Thus, it can be concluded that our impact estimates (ATT) is insensitive to unobserved selection bias and is a pure effect of diversification on households' income.

\section{Conclusionand Recommendations}

Livelihood diversification strategy is playing an important role to generate rural household's income. This study focused on the impact of livelihood diversification on rural household's income in Kamba and Arbaminch Zuria woreda in Gamo Zone, Southern Ethiopia. The study is conducted by using a cross-sectional research approach. This study employed multi-stage random sampling technique, a sample size of 400 household individuals from 6 sample kebeles were selected. To measure the impact of livelihood diversification on rural household income Propensity score matching (PSM) econometric model was used. To measure the average treatment effect on the treated (ATT) for intended outcome variable, a logit model was estimated in order to get the propensity scores.

The logistic regression result shows that diversification is significantly influenced by six variables. These variables are age, sex, religious, education in year, number of times the household received extension service in a year and access to market of the household head. Among these variables number of times the household received extension service in a year and access to market negatively affect diversification of the household income. The next task in propensity score matching technique is checked by the common support condition and it is achieved on the region of common support and Kernel with band width 0.1 results had low $\mathrm{R}^{2}$ equal value, large number of sample size and balancing insignificant test.

The values of the likelihood ratio test of the repressors in the logit model of propensity score estimation before matching at less than $1 \%, 5 \%$ and $10 \%$ significant level, respectively and after matching are not significant after matching $(\mathrm{p}=0.005)$. In other words, the likelihood ratio notes that the null hypothesis is not rejected after matching. Moreover, Propensity score matching (PSM) econometric model results was found that diversification brought statically significant effect in households' total annual income. Thus, it can be concluded that our impact estimates (ATT) is insensitive to unobserved selection bias and is a pure effect of diversification on households' income. Based on the results, discussion and conclusion, the following recommendations can be drawn at policy level and also at the local level of the Government.

Men household heads were the most participant in livelihood diversification than the female headed households' and the men household heads are the most dominate in the households' income. So, it should be recommended to increase the participation of women in livelihood diversification activities through creating employment opportunities, and making familiarity with recent livelihood diversification strategies to boast up their income. Education is an important issue in livelihood diversification. It is the key to success in the future and to have many opportunities in our life. So, the better the educational status, the analytical and information processing capacity of farmers increases which in turn encourage them to diversify their livelihood strategies. Frequency of contact with extension agent has a chance to diversify different livelihood activities so as to increase households' income. The researcher recommends that, the special package program has to be designed so as to promote off- 
farm and non-farm activities in the rural areas besides farming and should be incorporated among the major rural extension programs.

\section{References}

Abimbola A., and Oluwakemi O., (2013).Livelihood diversification and welfare of rural households in Ondo State, Nigeria.Department of Agricultural Economics, University of Ibadan, Oyo State, Nigeria.

Barrett, C. B., T. Reardon and P. Webb (2001). "Nonfarm income diversification and household livelihood strategies in rural Africa: Concepts, dynamics, and policy implications." Food Policy 26(4): 315-331.

Caliendo, M. and Kopeinig, S. 2008. Some Practical Guidance for the Implementation of Propensity Score Matching, Discussion Paper No. 1588, University of Cologne.

Dehejia, R. H. and Wahba, S. 2002. Propensity Score Matching Methods for Non- Experimental Causal Studies: The Review of Economics and Statistics, Vol. 84, No.1, pp. 151-161.

Ellis, F. (1998).Household strategies and rural livelihood diversification.Journal of Development Studies, 35(1), 1-38. doi:10.1080/00220389808422553

Fassil Eshetu \& Elias Mekonnen (2016). Determinants of Off-farm Income Diversification and its Effect on Rural Household Poverty in Gamo Gofa Zone, Southern Ethiopia. Vol.8(10), pp. 215-227.

Heinrich, C., Maffioli, A. and Vazquez, G. (2010). 'A primer for applying propensity score matching. Impact evaluation guidelines', Technical Notes, No. IDB-TN-161. Washington, DC, Inter-American Development Bank.

Lanjouw JO and Lanjouw P. (2001). The rural non-farm sector: Issues and evidence from developing countries. Agricultural Economics, 26(1): 1-23.

MelkamuMada and MesfinMenza (2015). Determinants of Rural Livelihood Diversification among Small-Scale Producers: The Case of Kamba District in Ethiopia. Asian Journal of Research in Business Economics and Management Vol. 5, No. 5, pp. 44-52.

Nasa'i, D. H.,T.K. Atala, J.G. Akpoko, T.M. Kudi, \& Habib Sani (2010). Analysis of Factors InfluencingLivelihood Diversification Among Rural Farmers in Giwa Local Government Area of Kaduna state, Nigeria.I.J.S.N., VOL. 1(2), 2010: 161-165

National Plan Center report (2016/17). Addis Ababa, Ethiopia.

Omotesho, M.O. Adewumi and K.S. Fadimula (2010). Department of Agricultural Economics and Farm Management, Faculty of Agriculture, University of Ilorin, Nigeria Press

Readon, T. (1997).Using evidence of household of income diversification to inform study of rural non-farm labour market in African : World Development, vol 25, No: 735-47.

Riithi, N., A., (2015). Determinants of Choice of Alternative Livelihood Diversification Strategies in Solio Resettlement Scheme, Kenya.University of Nairobi.

Rosenbaum, P. R., \& Rubin, D. B. (1985).Constructing a Control Group Using Multivariate Matched Sampling Methods that Incorporate the Propensity Score.The American Statistician, 39, 33-38.

Sianesi, B. (2004). Evaluation of the active labor market programs in Sweden. The Review of Economics and Statistics Vol. 86, pp. 133-155.

Umunnakwe V., (2015). Determinants of Livelihood Patterns among Rural Youth in Jabalpur District of Madhya Pradesh, India.

World Bank (2003).Reaching the rural poor: A renewed strategy for rural development. Washington, DC: The World Bank.

Yamane, T. (1967).Statistics: An Introductory Analysis. New York: Harper and Row: 2nd ed.

Yibeltal Fentie (2008). "The Impact of Ibnat-Belessa Integrated Food Security Program on Household Food Poverty", M.Sc. Thesis presented to the School of Graduate Studies of Haramaya University.

Zerihun Berhane Weldegebriel (2017). Non-Farm Diversification in Ethiopia: What Determines Participation and Returns? Addis Ababa University, Ethiopia. 